\title{
DESIGN AND PERFORMANCE EVALUATION OF JOJOBA OIL EXPELLING MACHINE
}

\author{
M. M. Badr*
}

\section{ABSTRACT}

Biodiesel is a type of biofuel that is appropriate for use in diesel engines. The non-edible vegetarian oil of the jojoba tree (Simmondsia Chinensis) is cultivated in tropical and subtropical climates worldwide and has the potential for use as a commercially applicable alternative to diesel. Jojoba oil is a renewable fuel that is environmentally friendly and can be readily produced. The main aim of this study is design and the performance evaluation of a expelling machine for extracting the oil jojoba as an alternative energy resource in terms to reduce the required pressure and power consumption and obtain significant productivity improvements. The press screw was designed square-shaped threads to obtain flexible motion with high transmission efficiency compared with that of the other threads. The effective stroke length of the press screw was gradually decreased from the feed port to the discharge end by increasing the screw depth to conform the requisite amount of jojoba seeds. Based on this design, can be used a planetary transmission system to transfer the largest torque during extraction process that ensure lower energy consumption at lower speeds in comparison with the conventional power transmission systems. The performance of the oil expelling machine was studied under the rotation screw speed and press clearance between screw and press barrel. Performance evaluation of the machine was carried out in terms of the throughput capacity, extraction efficiency and specific energy. The jojoba oil expelling machine has been manufactured with a throughput capacity of $135.85 \mathrm{~kg} . \mathrm{h}^{-1}$ and a machine efficiency of $88.55 \%$ furthermore the lowest value of energy requirement was $40.48 \mathrm{~kW} \cdot \mathrm{h} \cdot \mathrm{Mg}^{-1}$ by decrease of $18.47 \%$ by operating the oil expelling machine at rotation speed of $65 \mathrm{rpm}$ with $2 \mathrm{~mm}$ press clearance.

\section{INTRODUCTION}

xtracting different vegetable oils for biodiesel production is a
promising approach for internal combustion engines. Because of an
increase in fossil fuel prices and their greenhouse gas emissions,

*Assistant professor of Agric. Eng., Fac. of Agric., Zagazig Univ. Egypt. 
a new global awareness regarding energy production principally from renewable sources has become increasingly common. Jojoba oil has important physicochemical properties, and its performance properties are similar to those of diesel; thus, it could be mixed with fuel and provide major power without considerable changes in engine design. In addition, jojoba oil is known as an unpolluted oil, and its pretreatment for use as a biofuel is less complicated than that of other bio-oils. The jojoba tree is called the green gold tree because it can contribute to increasing the national income in poor countries. Jojoba plants vary from all known oil plants in the sense that its seeds include $40-50 \%$ of a unique oil-wax, which is more than twice the percentage of soybeans and slightly more than the percentage of most oilseed crops (Al-Widyan and Al-Muhtaseb 2010). Jojoba helps in resisting desertification, is durable and drought tolerant, grows in soils of uncertain fertility, resists salinity, and does not require expert cultivation equipment and thus can be easily produced. Jojoba oil is practically colorless and odorless and is unique among all known seed oils because it is not a fat but a liquid wax. Today, jojoba is applied in many everyday industrial uses, such as cosmetics, pharmaceuticals, lubricants, food, electrical insulators, foam control agents, heating oil, plasticizers, and fire retardants. Where, oil can be harvested from oilseeds via mechanical methods or solvent extraction. During the mechanical expression of oil, the liquid is forced out of liquid-containing solids, there by separating the liquid from a liquid-solid material (Pradhan et al., 2011 and Savoire et al., 2013). Mechanical technique is preferable to the solvent process because it is economical and has a chemical-free product. In addition, the equipment is simple, safe, and well-constructed and can readily be maintained. Moreover, this method can be adapted readily for various different types of oilseed. Also, the expulsion process is continuous, and the product is extracted within a few time of starting the processing operation therefore is characterized by a high production rate (Pradhan et al., 2011). A press screw is a preferable mechanical expression method because it is safe, flexible and continuous as well high yielding of oil recovery, and its extraction capacity can range from upto $45 \mathrm{~kg}$ per hour for a raw materialrelated expeller type, which is widely used for high-value oils and biofuel purposes in developing countries. (Chapuis et al., 2014). Indeed, cold 
pressing is preferred for straight vegetable oil production, whereas purification pretreatments are required to produce quality fuel used in diesel engines, especially for small-scale installations (Blin et al., 2013). Both the machine capacity and oil yield from mechanical pressing can be affected by the operating parameters and raw material and in turn affect process performance, mainly the rotational speed of the shaft and the clearance (diminution between the cage and screw shaft). Thus, parameter optimization should be performed to optimize the capacity and pressure impact. The screw rotation speed is an operating parameter that does not directly affect press execution. This parameter changes based on variations in the temperature and pressure in the barrel. Increasing the screw rotation speed leads to a decrease in pressure and an increase in temperature (Savoire et al., 2013). A meaningful positive relationship has been observed between an increase in material throughput and the oil recovery. Obviously, the material throughput is symmetric to the speed of the screw. Moreover, the energy consumption is affected by the seed oil concentration, especially at low oil contents. So, the vital relationship between energy efficiency and oil recovery must be considered to optimize the strategy of oilseed production, particularly when oil and press cake are utilized as energy sources. In this case, the oil expression cost will decrease (Chapuis et al., 2014). The energy of jojoba oil is 42.4 MJ.kg-1, which ranks as significant among all vegetable oils. An equally significant aspect is that jojoba meal has a high heating value 15.34 MJ.kg-1 (Huzayyin et al., 2004).

The overview on existent constructions of the oil extraction technique revealed a low throughput and extraction efficiency of the machine of 32.67 kg.h-1 and $62.22 \%$, respectively though it has high power required to operate screw shaft. So, there was an insistent require to develop an effective jojoba oil extraction machine for small- and medium-sized industries and to avoid previous prominent negative points in addition to use of locally materials with domestic technology as well to provide of requisite spare parts. This paper bridges the gap in our understanding of jojoba oil by providing a modified design for an expelling machine and the experimental parameters for a pilot-scale press screw as the alternative 
energy resource. Thus, the objectives of this research are summarized in design an appropriateness expelling machine to extract jojoba oil, improvement some operating parameters such as screw speed and press screw clearance affecting the performance of the designed machine as well reduce consumption in terms of energy requirements.

\section{MATERIAL AND METHODS}

The study was executed to develop and estimate the screw press performance for the extraction of crude oil from jojoba seeds. Therefore, the main objective of this study was to design and evaluate performance of the manufactured machine for extracting the oil jojoba as an alternative energy resource. The experiment was conducted at the Faculty of Agriculture, Zagazig University, Egypt. A series of experiments were performed and different parameters were studied on a pilot-scale screw press. The developed machine has an improved effective power transmission system using planetary gearboxes that provide for efficient operation at lower speeds and produce a high amount of transported torque to the screw press compared with that of the standard spiral gearbox used in the traditional designs. This increase in efficiency is caused by the shared load transmission by several planet gears.

\subsection{The jojoba plant:}

jojoba plant and also known as simmondsia chinensis, typically grows to 1-2 $\mathrm{m}$ with a broad dense crown, average Jojoba yield is around 1450 $\mathrm{Mg} / \mathrm{fed}$, world demand is estimated at between 64,000 and 200,000 $\mathrm{Mg}$ /year. Jojoba seeds have an oval oblong to oval seed produced by the female jojoba plant weighing from $0.50-1.50 \mathrm{~g}$ with a diameter of 5-15 $\mathrm{mm}$ and which at maturity is red brown with a wrinkly surface. Mature seeds contain of $30 \%$ protein, $45 \%$ liquid wax esters, $10 \%$ moisture content and $15 \%$ carbohydrate and fiber. Crude jojoba oil seems as a golden liquid with a a slight fatty scent at room temperature. The oil extracted from jojoba, $45 \%$ by weight wax in seed, is a single unsaturated oil consists of non-glyceride esters form almost completely of alcohols and straight chain acids. The world demand of Jojoba oil which is extracted from seeds is about 200 thousand $\mathrm{Mg}$ per year, the production covers only 5\% of the requirement, and jojoba oil regards a non-conventional potential energy 
resource that can be used as a biofuel in many industrial applications. so, Attention to this plant it is a great investment opportunity.

\section{2. developed machine:}

The jojoba oil expelling machine was designed to have the following components: feeding hopper, press screw, oil outlet opening, a cake drainage zone, planetary gearbox, electric motor and main frame as clarified in Fig. 1. Development was targeted towards increasing the oil production and machine efficiency and reducing the expense of constructing the modified machine. Through this modification, jojoba seeds entering the hopper are subjected to gradually increasing pressure as they move toward the exit end of the press, and the crude oil is extruded through a screen drilled on the vessel. The oil drainage hole has a larger diameter outside the vessel, and this diameter increases to a few millimeters in thickness to ensure maximum conveyance and efficient pressing.

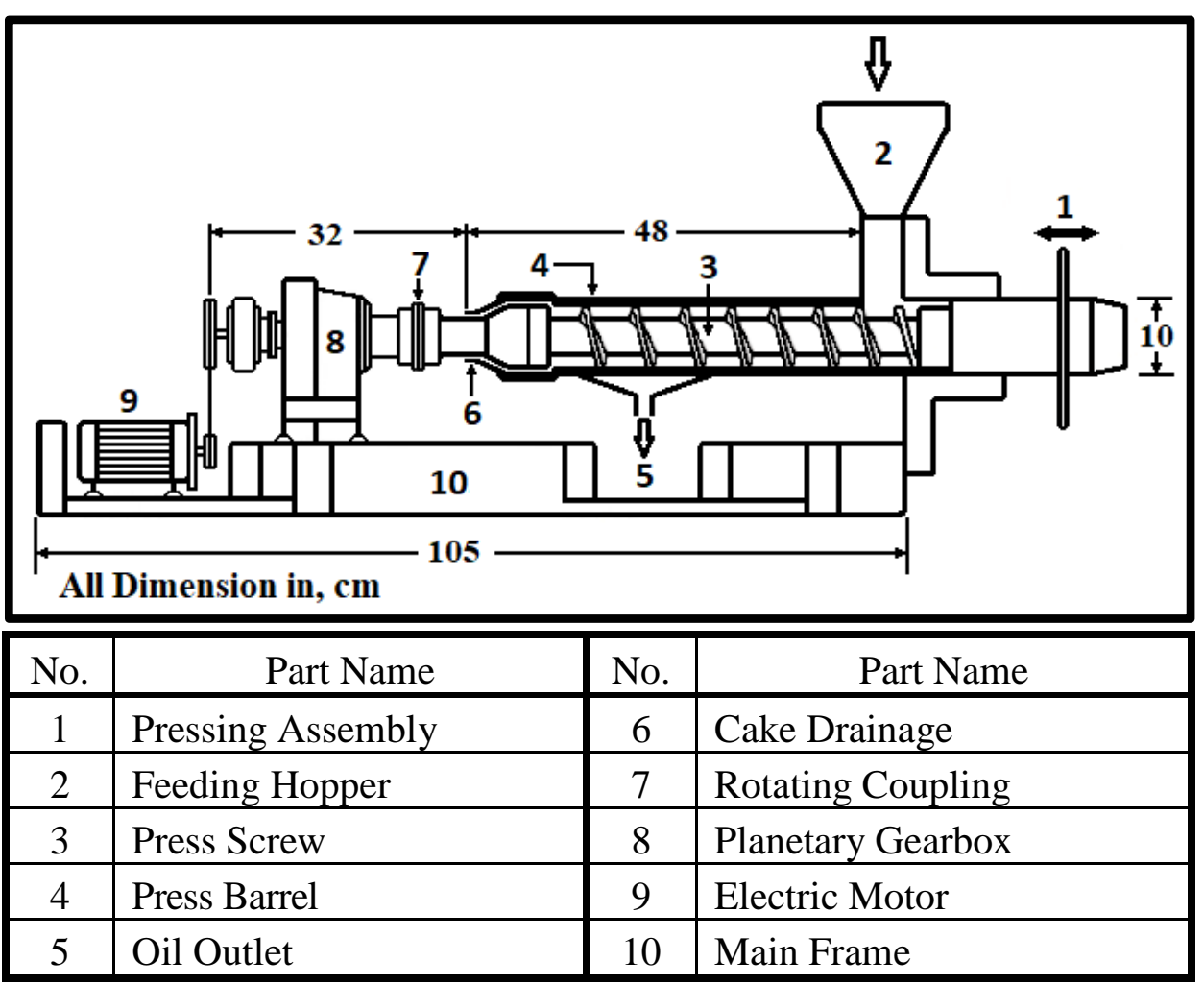

Fig. (1): A front view of jojoba oil expelling machine. 


\section{$\underline{\text { 2. Methods }}$}

The study was executed to develop and estimate performance of the expelling machine for the extraction of crude oil from jojoba seeds. This design has press screw system it is driven through a planetary transmission used to transfer the largest torque by lower operating energy that ensure an efficient operation at lower speeds and produce a high amount of crude oil compared to the other power transmission systems. Based on this criterion, the worm shaft was designed square-shaped threads to achieve high transmission efficiency compared with the other threads, in addition to gradually decrease the effective stroke length of this shaft by increasing the screw depth to adapt the demand amount of jojoba seeds.

\subsection{Design Considerations of Expelling Machine:}

Jojoba oil expelling machine was designed to have the following components: press screw to ensure maximum conveyance, the cylindrical barrel to accommodate the require quantity of raw material then, the hopper is designed to balance the amount of seeds to be pressed during extraction process. In addition, included the desire to design both the electric motor power, conical cake drainage zone and oil container. These considerations also achieved a strong main frame to ensure structural stability and strong support for the machine parts, according to (Ojolo et al., 2012).

\subsubsection{The Press Screw}

The press screw is main section of the machine that relocates the seeds, which are received from the hopper and transmitted to the cake discharge zone, where processing occurs. The capacity of the press screw, $\mathrm{Q}_{\mathrm{s}}$ was calculated using the following equation:

$$
\begin{aligned}
& \qquad \boldsymbol{Q}_{\boldsymbol{s}}=\left(\boldsymbol{A}_{\boldsymbol{m}}-\boldsymbol{A}_{\boldsymbol{r}}\right) \boldsymbol{p}_{\boldsymbol{s}} \boldsymbol{\rho n} \boldsymbol{\psi} \boldsymbol{C} \\
& \mathrm{Q}_{\mathrm{s}}=\left(7.08 \times 10^{-3}-4.42 \times 10^{-3}\right) \times 0.10 \times 615 \times 75 \times 0.30 \times 60=220.85 \mathrm{~kg} \cdot \mathrm{h}^{-1} \\
& \text { Where; } \mathrm{A}_{\mathrm{m}} \text { and } \mathrm{A}_{\mathrm{r}} \text { are major and root of screw area. } \\
& \mathrm{p}_{\mathrm{s}} \text { and } \rho \text { are pitch screw and bulk density of seeds. } \\
& \mathrm{n}, \psi \text { and } \mathrm{C} \text { are the screw speed, loading efficiency and inclination factor. }
\end{aligned}
$$

\subsubsection{The Press Barrel:}

The press screw is surrounded by a barrel which is cylindrical, the clearance between the barrel and the screw press is taken to be $2 \mathrm{~mm}$ and the length of the barrel is equal to the length of the press screw. Thus, volume of the barrel is $0.008 \mathrm{~m}^{3}$. The barrel carries the oil outlet sieve at a 
region close to the end of the screw. The region of the outlet is slightly recessed by $2 \mathrm{~mm}$, by boring, to prevent the excessive back flow of oil from the caking or pressing region into the incoming feed and the overall mean thickness of the barrel is $20 \mathrm{~mm}$.

$$
M=\rho_{S P} \times V_{S P}
$$

Where; $M$ is mass of jojoba seeds that barrel can contain, $\rho_{S P}$ is bulk density after pressing process and $\mathrm{V}_{\mathrm{SP}}$ is volume of pressed seeds, respectively.

$$
V_{S P}=V_{I B}-V_{B T}
$$

Where; $\mathrm{V}_{\mathrm{IB}}$ is inner volume of press barrel and $\mathrm{V}_{\mathrm{BT}}$ is inner volume both of root diameter and winding of screw shaft.

$$
V_{B T}=V_{S S}+V_{S W}
$$

Where; $\mathrm{V}_{\mathrm{SS}}$ is volume of screw shaft and $\mathrm{V}_{\mathrm{SW}}$ is volume of shaft winding.

In that case, $\mathrm{V}_{\mathrm{BT}}=4.2 \times 10^{-4}+4.42 \times 10^{-3}=4.84 \times 10^{-3} \mathrm{~m}^{3}$

$\mathrm{V}_{\mathrm{SP}}=7.85 \times 10^{-3}-4.84 \times 10^{-3}=3.01 \times 10^{-3} \mathrm{~m}^{3}$ and $\mathrm{M}=977 \times 3.01 \times 10^{-3}=2.94 \mathrm{~kg}$.

\subsubsection{The Seed Hopper}

The hopper design was dependent on the volume of a pyramidal frustum with a square base. Volume of the hopper was determined using the following formula: $\quad \boldsymbol{V}_{\boldsymbol{H}}=\boldsymbol{V}_{\boldsymbol{F}}+\boldsymbol{V}_{\boldsymbol{B}}$

Where; $V_{H}$ is volume of seed hopper, $V_{F}$ is volume of frustum and $V_{B}$ is volume of a rectangular base attachment.

$$
V_{F}=\frac{(\boldsymbol{A H}-\boldsymbol{a h})}{3}
$$

Where; A is the upper base's area, a is the lower base's area, $\mathrm{H}$ is the total height and $h$ is the height of bottom opening. Thus, volume of the seed hopper can be estimated through $\mathrm{V}_{\mathrm{H}}=5884.67+472.50=6357.17 \mathrm{~cm}^{3}$, this volume is suitable to contain the required quantity of jojoba seeds.

\subsubsection{The Conical cake drainage zone:}

Can be estimated the oil recovery using equation of the press screw capacity which was previously estimated in addition to the oil ratio of seeds and expected machine efficiency of at least $85 \%$.

$$
\begin{gathered}
\mathbf{0}_{\mathbf{r}}=\mathbf{Q}_{\mathbf{s}} \times \mathbf{0}_{\mathbf{c}} \times \boldsymbol{\eta}_{\mathbf{m}} \\
\text { Or }=220.85 \times 0.45 \times 0.85=84.48 \mathrm{~kg} \cdot \mathrm{h}^{-1}
\end{gathered}
$$

The mass flow rate of the compressed cake, $\mathrm{m}_{\mathrm{o}}$ through the conical zone is determined as the difference between capacity of the press screw and mass flow of oil extracted as follows: $\mathrm{m}_{\mathrm{o}}=220.85-84.48=136.37 \mathrm{~kg} \cdot \mathrm{h}^{-1}$. 
The density of cake is assumed to be equal to the solid density of the seed, $\rho_{\mathrm{s}}$ which is $977 \mathrm{~kg} / \mathrm{m}^{3}$, thus the volume flow of cake, $V_{\mathrm{o}}$ through the constriction nozzle is estimated as shown:

$$
\mathrm{V}_{\mathrm{f}}=\frac{\mathrm{m}_{\mathrm{o}}}{\rho_{\mathrm{s}}}=\frac{136.37}{977}=0.14 \mathrm{~m}^{3} \cdot \mathrm{h}^{-1}
$$

One of the important design criteria is the estimation shaft diameter of the press screw as well as the calculation of the pressure required value to overcome the constriction at the nozzle which lies at the end of the press screw as follows:

$$
P_{r}=\frac{F_{0} \times p_{m} \times n}{V_{f}}=21.43 \mathrm{Mpa}
$$

Assuming velocity of cake through the constriction zone is equal to the load propulsion speed of the screw, according to (Al-Hamamre and Rawajfeh 2015). evidenced that the end pressure of a press screw varies from 4 to 35 $\mathrm{MPa}$. Furthermore, From the value of constriction area can be calculated the constriction nozzle diameter which is estimated by $50 \mathrm{~mm}$ with a safety factor of 2 to allow for maximum oil extraction.

\subsubsection{Determination of Electric Motor Power:}

The electric motor of the extraction machine is selected based on the load characteristics of this machine. The electric motor is the selected power output of the motor using gear box and is obtained by the service factor is from 1.0 to 1.5 according to, (Akerele and Ejiko 2015). A service factor, fs $=1.50$ is selected, it was assumed that the electric motor operates continuously for at least 10 hours. The motor power, $\mathrm{P}_{\mathrm{m}}$ required to drive the press screw was evaluated using the following equations:

$$
F_{a}=F_{c m} \frac{(\cos \alpha-\mu \sin \alpha)}{(\mu \cos \alpha+\sin \alpha)}
$$

Where; $\mathrm{F}_{\mathrm{a}}$ is total axial force acting on the screw threads.

$\mathrm{F}_{\mathrm{cm}}$ is force needed to crush and move the jojoba seeds.

$\alpha$ and $\mu$ are screw thread lead angle and friction factor (steel from 0.50 to 0.80 ).

$$
T=F_{a} \frac{d_{p}\left(\mu \pi d_{p}+L\right)}{2\left(\pi d_{p}-\mu L\right)}
$$

Where; T is the torque acting on a press screw, $d_{p}$ is pitch diameter and $L$ is length of the press screw, $\mathbf{P}=\mathbf{2} \boldsymbol{\pi} \mathbf{N T}$

Where; $\mathrm{P}$ is power desired to drive the screw, $\mathrm{N}$ is rotating speed of the screw. 


$$
P_{m}=f_{s} \times P=1.5 \times 3.43=5.15 \mathrm{~kW}
$$

The electric motor is designed for continuous-duty operation at full-load, this motor would draw a 9.19-A current with a power rating of $5.50 \mathrm{~kW}$.

\subsection{Operation of the Jojoba Oil Expelling Machine}

The essential objective of the screw press machine is to generate force to extract oil from the seeds. A jojoba expelling machine has a hopper to feed the jojoba seeds into the screw press chamber, whereas a press shifts the seeds across a die where the pressing process occurs. The expelled oil is gathered at the oil outlet, and the pressed cake is collected at the die slot. The oil discharge zone is far from the cake evacuation zone. At the cake drainage zone, cake stress is at a maximum. Thus, if the oil drainage tears were drilled close to the cake drainage zone, then the tears could easily become stifled with cake. The working drawings of the machine is clarified in Figure 1. The machine is powered using a three-phase electric motor with $5.5 \mathrm{~kW}(7.48 \mathrm{hp})$, which is capable of drawing a full-load current of 9.19 A over 10 working hours. The expected capacity of the expelling machine is $1358.5 \mathrm{~kg}$. This design will improve the performance of the expeller and the machine and deliver an efficiency greater than $89.44 \%$. The oil flow is $906.97 l$ during the operation period. This expelling machine is conceived as an advance over the present machine and presupposes the inclusion of convenient technology for manufacturing, practicability, and maintenance strategy.

\subsection{Performance Indicators:}

The performance indicators that were estimated are the throughput capacity, extraction efficiency and specific energy.

\subsubsection{Throughput capacity:}

Throughput capacity quantifies the machine's capability in terms amount of the jojoba seeds, $m$ it can process per unit time, t. Can be calculated as follows.

$$
\mathbf{C}=\frac{\mathbf{m}}{\mathbf{t}}
$$

\subsubsection{Expelling machine efficiency:}

Machine efficiency, $\eta_{\mathrm{m}}$ is obtained from weight of crude oil collected, $\mathrm{W}_{\mathrm{o}}$ to weight of oil yield, $\mathrm{O}_{\mathrm{y}}$ in the test seed, which is given by:

$$
\eta_{\mathrm{m}}=\frac{\mathrm{w}_{\mathrm{o}}}{\mathbf{0}_{\mathrm{y}}} \times 100
$$


Hence, the oil yield in the test material is calculated by multiplying weight of the seeds processed, $\mathrm{W}_{\mathrm{s}}$ in oil content percentage of jojoba seeds, $\mathrm{C}_{\mathrm{P}}$ which was estimated of $45 \%$.

\subsubsection{Specific energy:}

$$
o_{y}=W_{s} \cdot C_{P}
$$

The energy consumption can be calculated using the following equation:

$$
\mathbf{E}_{\mathbf{s}}=\frac{\mathbf{P}_{\mathbf{m}}}{\mathbf{C}}
$$

\section{Results and Discussion}

The obtained results will be discussed in relation to the following points.

\subsection{Influence of the screw speed on the throughput capacity:}

The representative throughput capacity rate values versus the screw speed is provided in Fig. 2. The obtained results show that increasing the screw speed from 55 to $75 \mathrm{rpm}$ measured at different press clearances of 1.5, 2.0, 2.5 and $3.0 \mathrm{~mm}$ increased the throughput capacity by $59.47,62.50,71.50$ and $46.94 \%$ respectively, at constant seed moisture content of $10 \%$.

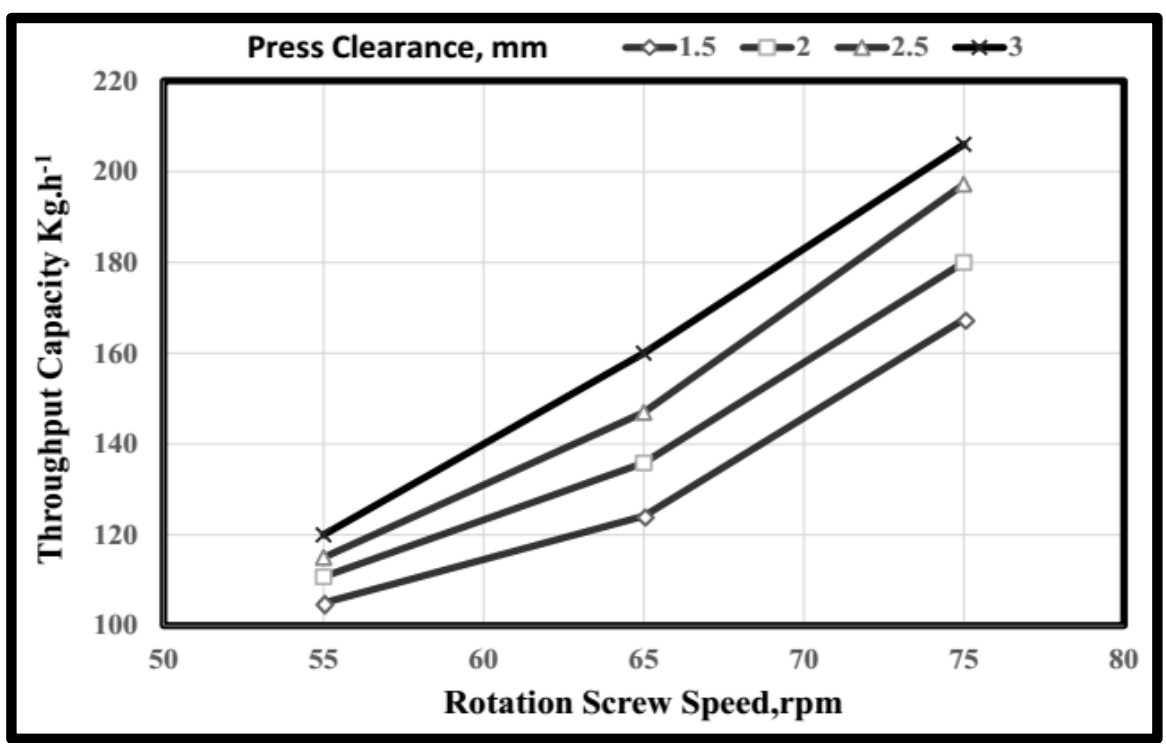

Fig. 2: Effect of the screw speed on the throughput capacity.

The machine throughput capacity increased as the screw speed increased because of the increase in seed flow through the screw feeding entrance that lead to increase the extraction rate because of the increase in the crude oil flow through the drainage outlet at the same unit of time. 


\subsection{Influence of the press screw speed on the machine efficiency:}

The values shown in Fig. 3 clarify the effect of the screw speed on the overall machine efficiency. The obtained data show that increasing the rotation speed of the press screw up to $65 \mathrm{rpm}$ increases the overall efficiency, whereas further increase in screw speed, even to $75 \mathrm{rpm}$, will decrease the machine efficiency. Increasing the screw speed from 55 to 65 rpm measured at different press clearances of 1.5, 2.0, 2.5 and $3.0 \mathrm{~mm}$ increased machine efficiency by a rate of $14.29,18.07,16.44$ and $15.49 \%$, respectively. Any further increase in screw speed more than 65 up to $75 \mathrm{rpm}$ measured at the same press clearances decreased machine efficiency by 7.50 , $11.91,10.59$ and $8.54 \%$, consecutively.

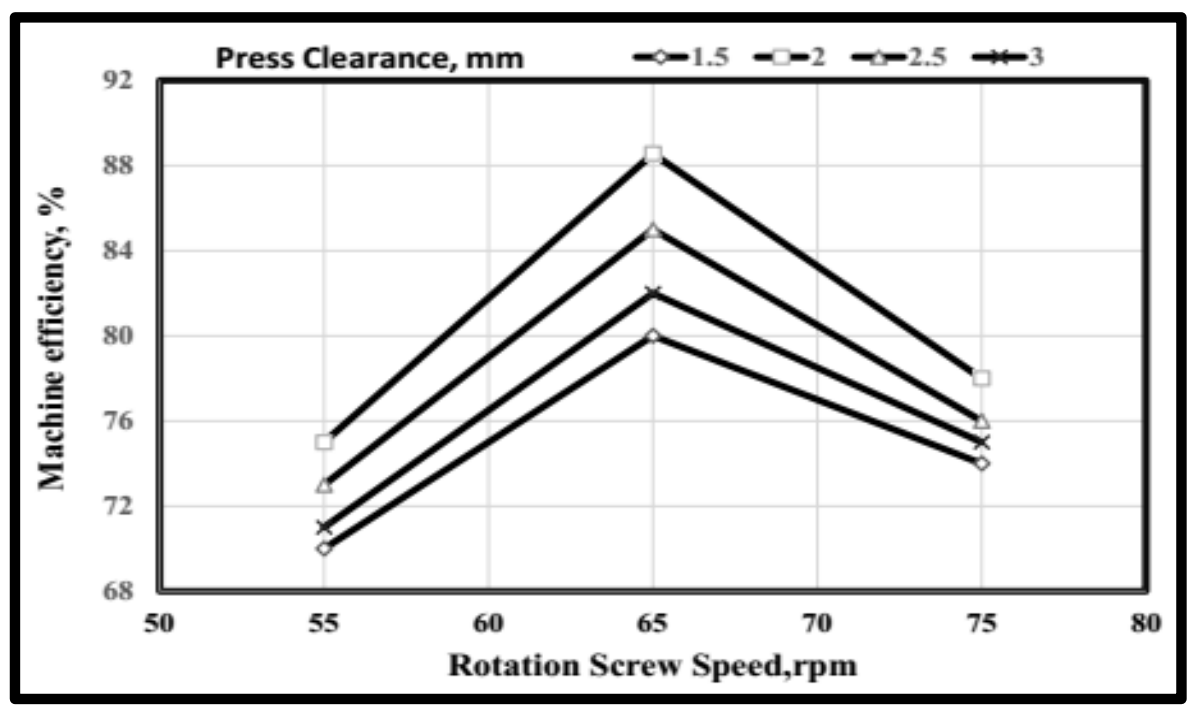

Fig. 3: Influence of the screw speed on the overall machine efficiency.

The extruder was effective because of its capacity to crush the jojoba seeds while pressing. The pressing zone reduced the size of the solid particles, and this mechanical action led to the release of a considerable amount of the oil. The reverse pitch screws pushed part of the mixture upstream against the general movement of the extruder, and this counter pressure ensured high efficiency of the separated oil above the metal filter.

\subsection{Influence of the press screw speed on the specific energy:}

Indeed, the press screw speed had a great effect on the energy requirements. This relationship is shown in Fig. 4. The obtained data show that increasing the screw speed from 55 to $75 \mathrm{rpm}$ measured at different press clearances 
of approximately $1.5,2.0,2.5$ and $3.0 \mathrm{~mm}$ decreased the specific energy from 52.38 to 32.85 , from 49.65 to 30.56 , from 47.82 to 27.89 and from 45.83 to $26.70 \mathrm{~kW} . \mathrm{h} . \mathrm{Mg}^{-1}$, respectively, at the same seed moisture content. The decrease in specific energy by increasing screw speed is attributed to smoothly and the easy cake flow from outlet opening as well the increase in throughput capacity that reduces energy requirements.

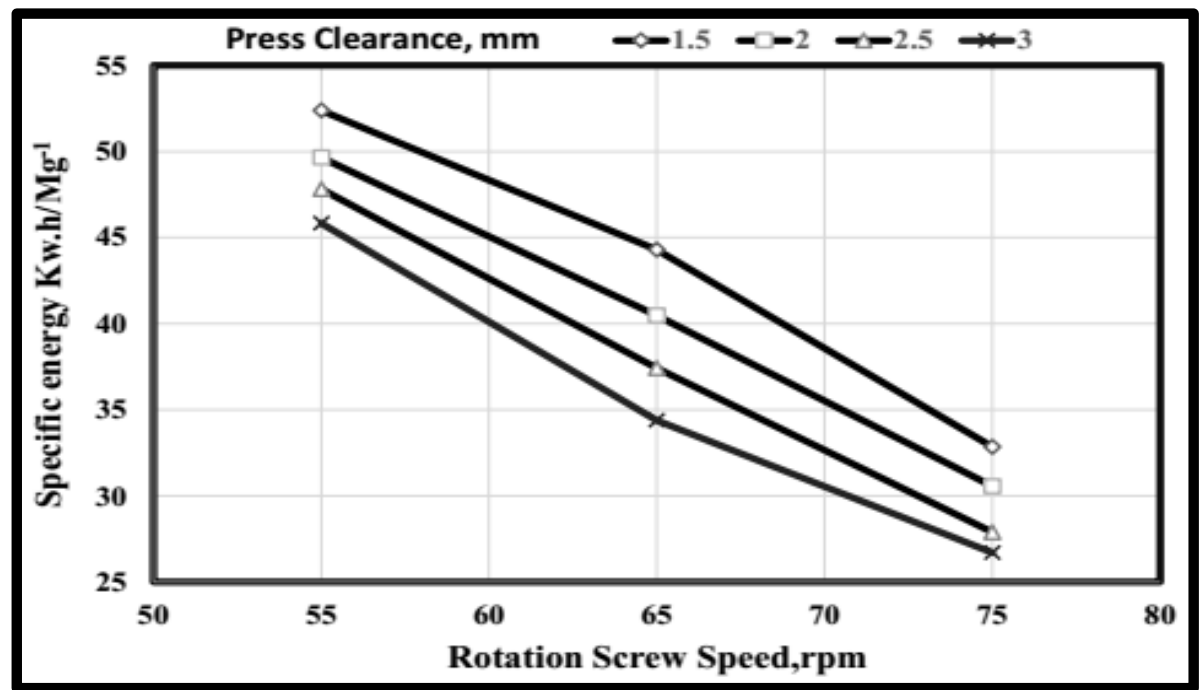

Fig. 4: Influence of the screw speed on the specific energy.

\section{CONCLUSIONS}

A jojoba oil expelling machine was designed and constructed using locally available and easily obtainable materials. The extraction machine was uncomplicated in its operation, maintenance and repair. Experiments were conducted to develop and evaluate the performance of the oil expeller to improve its efficiency which reached a maximum value of $88.55 \%$. The extraction machine can be used for jojoba oil extraction at a medium scale in rural and urban regions as well it is conceived as ideal, easily maintained and economic for commercial uses. The machine is powered using a 5.5 $\mathrm{kW}(7.48 \mathrm{hp})$ electric motor at full load with draw a 9.19 A current and can be operated for 10 working hours.

This design will enhance the performance of the expeller, and the machine is capable of delivering consumed energy by decrease of $18.47 \%$ with expected capacity of the expelling machine worth $135.85 \mathrm{~kg} \cdot \mathrm{h}^{-1}$ during extraction process. This machine is considered an improvement over 
existing machines and presupposes the availability of appropriate technology for manufacturing, operation and maintenance where the machine can be fabricated locally at a well-equipped machine shop.

\section{REFERENCES}

Akerele O. V. and S.O. Ejiko (2015): Design and construction of groundnut oil expeller. International Journal of Engineering and Computer Science, 4 (6): 12529-12538.

Al-Hamamre Z. and K. M. Rawajfeh (2015): Investigating the energy value of jojoba as an alternative renewable energy source. International journal of green energy, 12(4): 398-404.

Al-Widyan M. I. and M. A. Al-Muhtaseb (2010): Experimental investigation of jojoba as a renewable energy source. Energy Conversion and Management, 51(8): 1702-1707.

Blin J; C. Brunschwig, A. Chapuis, O. Changotade, S. S. Sidibe, E. S. Noumi and P. Girard (2013): Characteristics of vegetable oils for use as fuel in stationary diesel engines-Towards specifications for a standard in West Africa. Renewable and Sustainable Energy Reviews, 22: 580-597.

Chapuis A; J. Blin, P. Carre and D. Lecomte (2014): Separation efficiency and energy consumption of oil expression using a screwpress: The case of Jatropha curcas L. seeds. Industrial Crops and Products, 52: 752-761.

Huzayyin A. S; A. H. Bawady, M. A. Rady and A. Dawood (2004): Experimental evaluation of diesel engine performance and emission using blends of jojoba oil and diesel fuel. Energy Conversion and Management, 45(13): 2093-2112.

Ojolo S.J; J.I. Orisaleye and S.O. Ismail (2012): Design of a jatropha oil expelling machine. Journal of Emerging Trends in Engineering and Applied Sciences (JETEAS), 3(3): 412-419.

Pradhan R. C; S. Mishra, S. N. Naik, N. Bhatnagar and V. K. Vijay (2011): Oil expression from Jatropha seeds using a screw press expeller. Biosystems engineering, 109(2): 158-166.

Savoire, R; J. L. Lanoiselle and E. Vorobiev (2013): Mechanical continuous oil expression from oil seeds. Food and Bioprocess Technology, 6(1): 1-16. 


\section{الملخص العربـى}

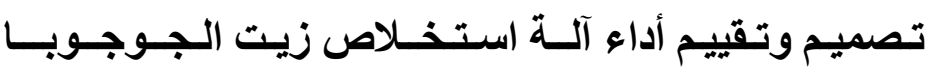

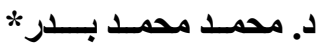

في إطار أزمة الوقود الحفرى المنتشرة فى العقود الأخيرة وتضاؤل احتياطات الطاقة المتاحة وتفاقم

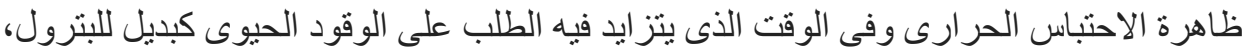

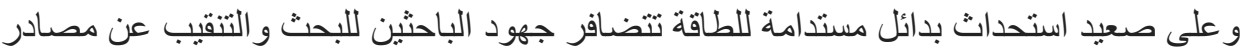
بديلة للطاقة وكان من أبرز هذه الدر اسات التي اتخذت منحى التطبيق في بعض الدّة الدول المتقدمة هي

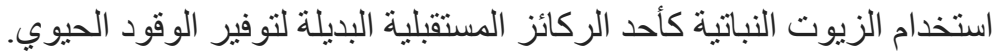

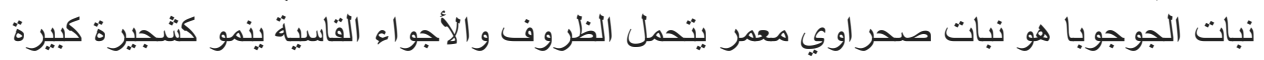

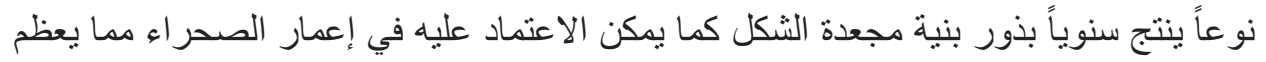

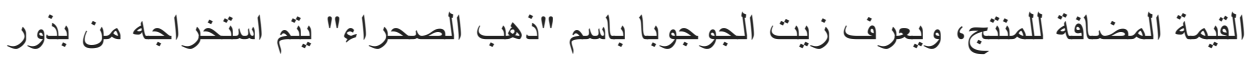

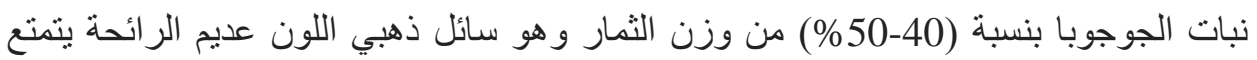

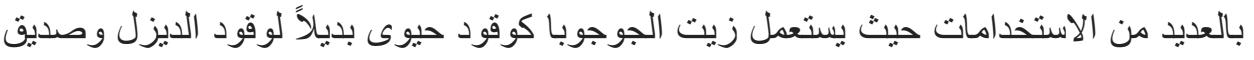
للبيئة لإحتوائه على كربون أقل مما يقلل م الانبعاثات الكربونية بعد عملية الاحتر اق كما بيتخدم

فى تزييت المحركات وفي مجال البتروكيماويات وصناعة الأدوية و المستحضر ات الطبية.

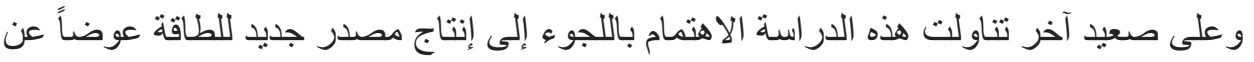

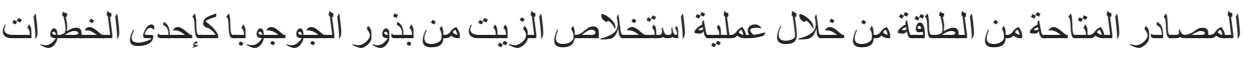
الأولى فى هذا المجال وذلك بوضع الأسس التصميمية لآلة الاستخلاص لتحقيق أعلى معدل مدل أداء بأقل طاقة مستهلكة أثناء عملية الاستخلاص وذاص وتمت عملية التصنيع بأحد الورش الخاصة بمدينة الزقازيق ـ محافظة الشرقية ـ مصر ـ فقد تبلور الهدف الرئيسى لهذا البحث من خلال تصميم بريمة الضغط على هيئة عمود لولبي ذو مقطع مستطيل الثكل لضمان التأثير الفعال مع استيعاب الكمية

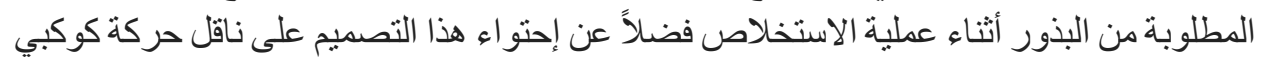

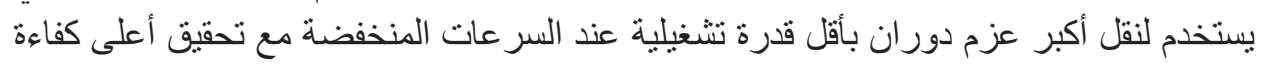

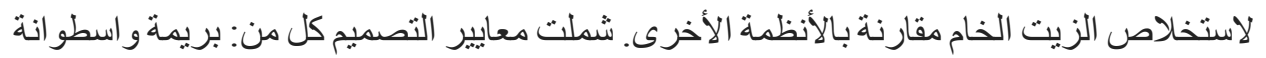

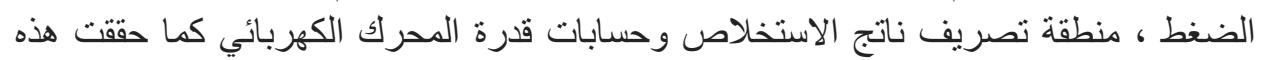

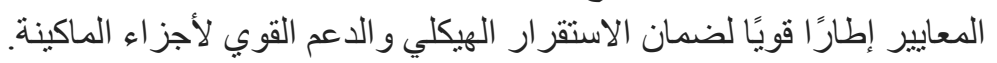
ولتقيم أداء الآلة المطورة التما أخذ ثلاثة سر عات دور انية لبريمة الضغط هي:

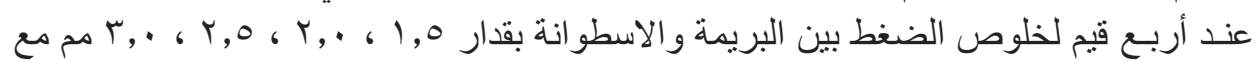
أخذ القياسات التالية: إنتاجية الآلة، كفاءة الاستخلاص ، الطين الطاقة المستهلكة. وتشير النتائج المتحصل

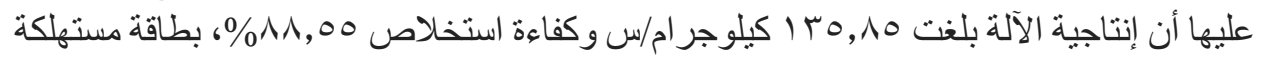

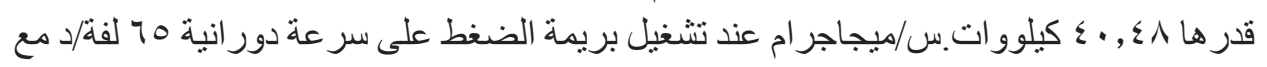

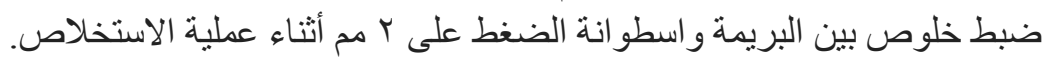

* قسم الهندسة الزراعية ـ كلية الزراعة - جامعة الزقازيق - مصر. 